doi http://dx.doi.org/10.18542/rmi.v13i21.9558

\title{
BAÚ DE MEMÓRIAS: O LEPROSÁRIO DE MARITUBA/PA EM MEIO A RECORDAÇÕES DE UMA EX-INTERNA (1940-1970)
}

\section{MEMORY CHEST: THE LEPROSARY OF MARITUBA / PA AMONG RECALLS FROM AN EX- INTERN (1940-1970)}

Moisés Levy Pinto CRISTO ${ }^{1}$

Universidade do Estado do Pará

Gercina Ferreira da SILVA ${ }^{2}$

Universidade do Estado do Pará

Maria do Perpétuo Socorro Gomes Avelino de FRANÇA ${ }^{3}$

Universidade do Estado do Pará

Resumo: O presente estudo visa refletir sobre as contribuições das narrativas de memória de exinternos do Hospital Colônia de Marituba/PA, nos anos de 1940 a 1970; memórias de um tempo vivido que permitem adentrar no universo cultural dessa instituição. Em formato de instituição total, o Hospital Cidade abrigou centenas de vidas para o tratamento da hanseníase. Utilizamos como materiais para a construção desta análise entrevistas de exinternos da instituição, imagens sobre a instituição e jornais. As narrativas aparecem como uma forma de ensinamento, que aliada às iconografias, textos e testemunhos, tornam-se importantes fontes de evidencia. Utilizamos como aporte teórico os autores: Bresciani e Naxara (2004), Bosi (1998), Burke (2017), Goffman (1994), Halbwachs (2003), Meihy e Holanda (1997). As narrativas e as imagens apontam experiências de vida do hanseniano, grupo que foi silenciado pela história brasileira. Marituba revela-se por memórias ágeis e pés cansados que ainda deixam marcas sobre as pedras da cidade.

Palavras-chave: Memória. Narrativas. História. Hanseníase. Marituba-PA.

\begin{abstract}
The present study aims to reflect on the contributions of the memory narratives of exinmates at the Hospital Colonia de Marituba/PA, from 1940 to 1970; memories of a lived time that allow to enter the cultural universe of this institution. In the form of a total institution, the City Hospital housed hundreds of lives for the treatment of leprosy. We used as materials for the construction of this analysis interviews with exinterns of the institution, images about the institution and newspapers. Narratives appear as a form of teaching, which combined with iconographies, texts and testimonies, become important sources of evidence. We used as a theoretical contribution the authors: Bresciani and Naxara (2004), Bosi (1998), Burke (2017), Goffman (1994), Halbwachs (2003), Meihy and Holanda (1997). The narratives and images point to life experiences of the leprosy, a group that has been silenced by brazilian history. Marituba is revealed by agile memories and tired feet that still leave marks on the stones of the city.
\end{abstract}

Keywords: Memory. Narratives. Story. Leprosy. Marituba/PA.

\footnotetext{
${ }^{1}$ Programa de Pós-Graduação em Educação (PPGED)/Universidade Federal do Pará (UEPA). E-mail: moiseslevypintocristo@gmail.com.

${ }^{2}$ PPGED/UEPA.E-mail: ferreiragercina@gmail.com.

${ }^{3}$ PPGED/UEPA. E-mail: socorroavelino@hotmail.com.
} 


\section{Introdução}

O presente artigo é recorte da pesquisa de dissertação de mestrado, na Linha de Saberes Culturais e Educação na Amazônia, do Programa de Pós-Graduação em Educação da Universidade do Estado do Pará. Este visa discutir as contribuições da memória em processos historiográficos, lembranças carregadas de sentimentos de um tempo vivido que foi marcado por alegrias, tristezas e saudades. Como um baú, a memória guarda recordações que marcaram um momento vivido, aquilo que é precioso, e que não está a prova de todos. Estas memórias das intérpretes, apresentadas com as iniciais CS e RT serão o fio condutor do presente texto e, quando apresentadas, permitirão adentrar o universo cultural dessa instituição.

Para a construção do presente trabalho, utilizei duas narrativas, comentadas no parágrafo anterior, "que se equiparariam aos outros suportes, sejam: escritos, estatísticos ou iconográficos" (MEIHY; HOLANDA, 1997, p.67). "E aqui as palavras tecem as histórias de vida, redesenham o passado para que os olhos de hoje possam ver e conhecer, admirar e aprender" (EIRÓ, 2017, P. 93). Alheadas as narrativas, buscamos dois jornais locais, a Folha do Norte, de 16 de janeiro de 1942, página 2, com o título "O governo da República entregou ao Estado o leprosário de Marituba - A inauguração do Nosocômio", e o jornal O Estado do Pará, também de 16 de janeiro de 1942, página 8, intitulado “A inauguração do leprosário de Marituba - como decorreram as cerimônias levadas a efeito ontem". Ambos descrevem os processos de inauguração e imagens sobre o local. Acrescentamos o uso de algumas imagens coletadas ao longo da pesquisa. Diante do exposto, procuramos lançar mão dos mais variados tipos de evidências (BURKE, 2017).

A memória está carregada de sentimentos referentes a um tempo vivido, memórias que trazem em si o saber de um passado que é vivificado em cada rememoração trazida pelo sujeito. Juntamente a essas memorias, as fotografias também podem assumir-se, em estudos historiográficos, como mais uma fonte, dentre "uma gama mais abrangente de evidências, na qual as imagens têm o seu lugar ao lado de textos literários e testemunhos orais" (BURKE, 2017, p.17).

O texto está demarcado pelas possibilidades e reflexões de como a memória de duas idosas ex-internas - que, em conjunto com as imagens fotográficas de seus baús, podem contribuir para a (re)constituição de um passado histórico, o da Antiga Colônia de Marituba/PA.

A antiga cidade hospital, que esteve imersa em campanhas de desenvolvimento nacional, foi proporcionada pelo governo Vargas (1935-1945), no período de 1930, quando foram fomentadas as construções de asilos-hospitais que abrigariam os infectados pela lepra (BRASIL, 1950). 
Destacamos que o termo lepra, será utilizado não no sentido pejorativo da palavra, pois esta palavra, que carrega em si um estigma social, deixou de ser utilizada a partir da Lei Federal $\mathrm{n}^{\mathrm{o}}$ 9.010/1995, sendo substituída pelo termo hanseníase. Utilizamos a palavra lepra devido aos documentos do período tratarem a hanseníase pela sua primeira denominação utilizada na humanidade.

Nesse período de governo, somaram-se, em construções e ampliações, um total de 40 hospitais colônias; dentre eles, emergia o Hospital Colônia de Marituba, inaugurado em 15 de janeiro de 1945, no estado do Pará. Em formato de instituição total (GOFFMAN, 1974), o local abrigou centenas de vidas para o tratamento de uma endemia, a lepra, sendo um espaço marcado por estigmas, memórias, histórias, saberes, momentos únicos que estão silenciados e pouco explorados.

Há sujeitos que enfrentam duplo estigma, o de ser ex-interno - antigo "leproso" - e o de ser "velho" - no sentido não pejorativo da palavra. "Velho" é denominação a ser tratada no decorrer do texto com o sentido de inscrever um ser humano que possui, segundo Bosi (1994), um "tesouro que é guardião", capaz de "refazer" ou reconstituir, por meio das memórias, os labirintos encontrados ao longo das histórias sociais.

Como suporte teórico, utilizamos os autores Bresciani e Naxara (2004), Bosi (1998), Burke (2017), Goffman (1994), Halbwachs (2003) e Meihy e Holanda (1997), que dialogam com a temática aqui proposta.

Valorizar as narrativas de velhos, que muitas vezes foram impedidos de sonhar, de se expressar e até mesmo de ensinar (BOSI, 1994), será ponto de partida; uma memória que se "oferece, que se submete à história e a ela oferece suporte documental importante para suas narrativas" (BRESCIANI; NAXARA, 2014, p. 11).

O artigo vem propor o uso de narrativas e seus guardados memoráveis, considerando-os como ensinamentos e "testemunho" de uma pessoa experiente, que "vem depor daquilo que viu, diante do ‘eu' que não viu” (HALBWACHS, 2003, p. 29), que podem contribuir em processos historiográficos de tempos pouco explorados.

\section{Hospital Colônia de Marituba (1940-1970): cidade ou prisão?}

No antigo espaço, ainda seguem a passos lentos, alguns ex-internos que resistiram e sobreviveram ao encarceramento estatal promovido pelas políticas públicas higienistas. Ex-internos da Colônia de Marituba, que estão marcados por memórias de isolamento, discriminação, educação e superação de vida. Esta trajetória de vida, marcada pela caminhada diária de experiências e 
vivências - como coloca Certeau (1998, p. 176), “[...] os passos moldam espaços. Tecem lugares [...]” - vem descrever algumas questões dessa teia institucional que foi a cidade hospital.

Bergson (2006) faz a comparação da memória com um aparelho fotográfico; como um foco possível para delinear a imagem, os fios da memória podem ser alcançados com mais nitidez em meio as narrações:

Pouco a pouco, ela aparece como uma névoa que se condensasse; de virtual, passa ao estado atual; e, à medida que seus contornos vão se desenhando e sua superfície vai ganhando cor, tende a imitar a percepção... não fosse algo que contrasta com o presente, nunca reconheceríamos por lembrança [...] (BERGSON, 2006, p.49).

Neste sentido, para compreendermos certos períodos por meio de recordações pessoais memória e imagens - , consideraremos as narrações, rancores, vinganças, fantasmas de morte e incertezas, encontrando-as em reticências de um passado distante cronologicamente, mas presente em meio às memórias dos ex-internos (BRESCIANI; NAXARA, 2004). Encontramos essas incertezas em meio às narrações de CS, interna em 1959, quando criança, aos 8 anos de idade:

"Olha, eu vou the dizer uma coisa, se a senhora não quiser 'deixar ela', a senhora pode levar, só que os próprios seus vizinhos vão se afastar da sua casa, porque ela tem que tomar remédio, porque ela tá doente" [...] Aí, a mamãe, coitada, ficou entre a cruz e a espada, porque ela queria que eu ficasse boa (CS, 2017).

A certeza estaria em fazer um tratamento proposto pelo Estado em favor de uma doença. Mas incerto seria seu futuro e de muitas outras pessoas que ainda iriam contrair uma doença marcada pelo terror e preconceito. Esse medo social está demarcado em meio as narrações de RT, interna em 1959, quando adolescente:

$\mathrm{Ah}$ ! "Tu sabe" que o pessoal no interior tem muito preconceito, naquela época todo mundo tinha muito preconceito [...] Inclusive a nossa casa [...] Eles tocaram até fogo na nossa casa, hoje em dia ainda "tem" um terreno lá que foi vendido, que o meu pai vendeu, mas o "pessoal" não quis morar na casa com medo, porque achavam que se "morasse" na casa iam ter hanseníase também, tocaram fogo na nossa casa (RT, 2018).

Após essas narrações, marcadas por incertezas e preconceito, o historiador traz em seu trabalho o compreender e o explicar o que não é dito, o que é invisível, devendo estar atento aos indícios, signos, traços, que contemplem seu trabalho de (re)constituição de um passado pouco conhecido por meio das memórias (BRESCIANI; NAXARA, 2004), pois na falta de documentos 
oficiais que pouco revelem sobre os labirintos do período, temos as memórias como "documento vivo" (MEIHY; HOLANDA, 1997).

Em meio a essas memórias, emerge o Hospital Colônia de Marituba/PA, terceiro espaço do Estado do Pará direcionado à segregação de pessoas infectadas pelo mal de Hansen. Distante 12 quilômetros da capital Belém, o local foi idealizado por Souza-Araújo - importante médico leprologista do período, o mesmo que também idealizou a Colônia do Prata em Igarapé-Açu em 1924 -, tendo o início de suas construções no ano de 1938, destinando-se inicialmente a 1.000 doentes, como mostra a imagem 1.

Imagem 1 - Leprosário de Marituba/PA - 1945

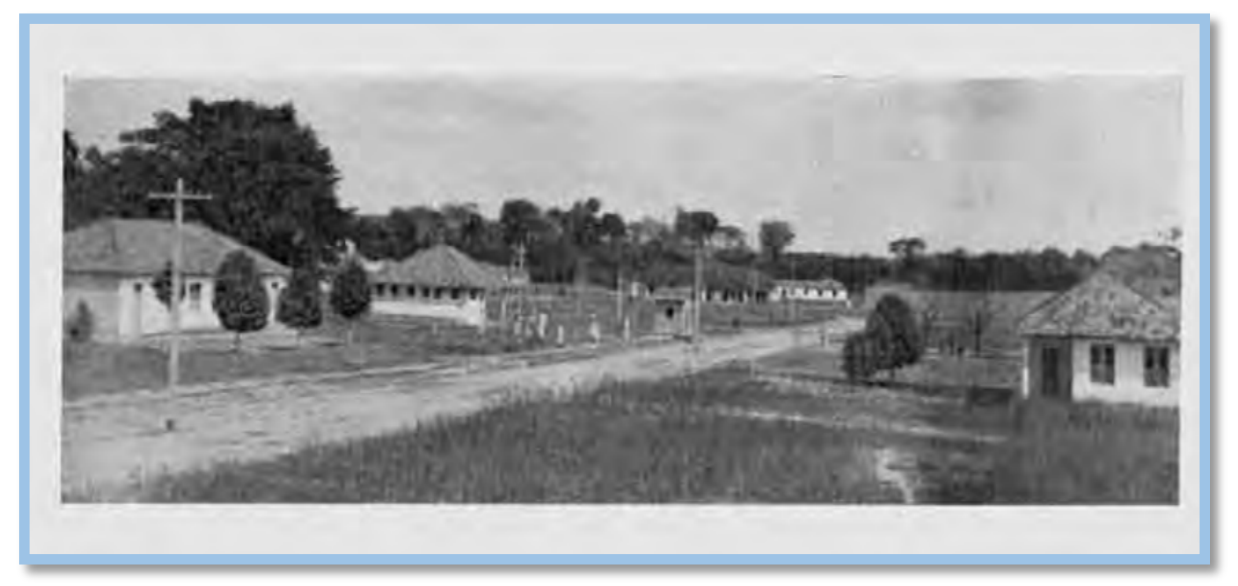

Fonte: História da lepra no Brasil, v. II, 1948, p.117.

O lugar foi edificado a 5 minutos da vila operária de Marituba, em uma área de $1 / 2 \mathrm{~km}$ de frente e $2 \frac{1}{2} \mathrm{~km}$ de fundo, totalizando 375 hectares de terras em mata virgem (SOUZA-ARAÚJO, 1941). As florestas, como podemos observar no horizonte da imagem, serviriam como barreiras naturais, objetivando conter qualquer tipo de fuga do doente (CASTRO, 2017).

A instituição teria sua inauguração em 15 de janeiro de 1942. O governo federal investiu nela a quantia de quatro mil contos. Foi construída em uma área vastíssima da vila de Marituba, com terreno próprio para agricultura - espaço pensado em produzir sua própria subsistência.

A sua inauguração foi noticiada pelos jornais da época, como a Folha do Norte e O Estado do Pará. O leprosário de Marituba foi entregue pelo Governo da República - com a presença de autoridades e imprensa -, por intermédio do Delegado do Departamento Federal de Saúde, o Dr. Valério Konder (FOLHA DO NORTE, 1924, p. 13). 
A inauguração aconteceu às 9 horas da manhã, no próprio espaço, com a presença de D. Jayme de Barros Câmara, Arcebispo de Belém, o qual realizou a cerimônia religiosa no novo prédio. Encerrando os discursos, falou o Dr. Paulo Cerqueira, nomeado como diretor do novo Leprosário de Marituba (O ESTADO DO PARÁ, 1942).

Após a entrega do espaço, o Interventor federal, acompanhado do Arcebispo, Contraalmirante Brito e Cunha, Capitão Tenente Raul Câmara e Comandante Bulcão Viana, percorreu de automóvel a instituição. Antes do encerramento, às 11 horas, serviram "frios, doces e gelados" (FOLHA DO NORTE, 1924).

O Hospital Colônia de Marituba contou com a seguinte estrutura: 16 pavilhões Carville modelo dos EUA -, 2 pavilhões de crianças, casa geminadas, cozinhas, refeitórios, área para diversão, área de abrigo para a administração, como noticia o jornal:

Tem ótimas instalações de água e esgoto, além de uma usina elétrica. Possui 16 pavilhões "carville" com capacidade para 28 doentes em cada um; 23 casas geminadas para abrigo de casais doentes e dois pavilhões para crianças.

Possui além disso, pavilhões de refeitórios, cozinhas, de diversões. Na zona intermediária, ficam as casas dos enfermeiros, irmãs de caridade, médico e funcionários da administração (A PROVÍNCIA DO PARÁ, 1942, p. 1).

Os pavilhões da Colônia apresentariam em torno de 28 leitos, cada um com 14 quartos com portas externas e sem janelas. Acomodações que abrigavam pessoas solteiras. Os mesmos eram organizados por faixa etária e por sexo. Havia os pavilhões que abrigavam o sexo masculino, pavilhões que abrigavam o sexo feminino, os que abrigavam os idosos e outros que abrigavam as crianças, como mostra a imagem 2.

Imagem 2 - Grupo de crianças leprosas e pavilhões coletivos

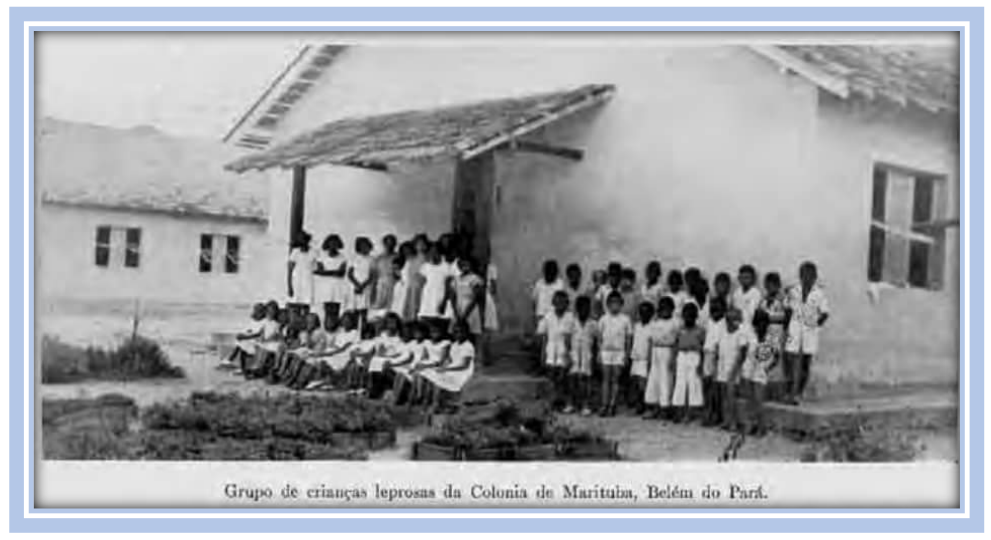

Fonte: História da Lepra no Brasil, v. II, 1948, p.118. 
O relato da intérprete informa a presença do espaço para crianças:

[...] Quando eu cheguei tinha... se eu não me engano... tinha dezessete crianças, mas tudo nessa faixa de oito, nove, dez, onze, até quatorze... tinha o pavilhão infantil [...] Aí, tinha os brinquedos, nós "tinha" um quarto lá que era só de brinquedo. Cada uma tinha seu brinquedo (CS, 2017).

A Colônia de Marituba foi inserida em meio ao cenário ditatorial. Dotada de características de uma política de internação compulsória, como vimos no relato inicial de CS, em que a rigidez com horários, a intolerância e a austeridade estariam presentes em seu cotidiano (CASTRO, 2017).

Quando "era" cinco horas ela chamava a galera, todas! A Ilária e todo mundo cuidava de seus deveres... Tinha os quartos, tinham que deixar varridos, tudinho... pra depois a gente [...] Desde pequenininho. A gente sabia de tudo, tudo era zelado lá. Lá tudo era limpo, lindo, porque ela era muito aciada (CS, 2017).

Eles vinham visitar [...] Todas quintas e domingos [...] Ninguém ficava aqui que não tivesse hanseníase [...] tinha aquele horário que a pessoa entrava pra visitar, por exemplo das 8 às 10, ou 12, não me lembro bem, mas quando dava aquele horário, se quisesse ficar até tarde com a sua família, tinha que ir ali, lugar que se chamava de parlatório, ficar sentado até dá a hora pra entrar de novo, ninguém comia aqui, ninguém fazia nada! (RT, 2018).

Podemos observar, em meio às narrações, dois momentos do cotidiano da instituição: horários e afazeres domésticos, assim como o controle de visitas aos internos. Essa memória, segundo Bresciani/Naxara (2004, p. 41), “encontra-se prisioneira da história ou encurralada nos domínios do privado e do íntimo, transformou-se em objeto e trama da história, em memória historicizada". Por intermédio de lembranças, encontramos a possibilidade de (re)criação de "quadros" - termo usado por Halbwachs - de um passado distante cronologicamente, contudo presente por meio de memórias. Por meio de recordações, podemos encontrar mais traços dessa instituição:

Ah, era um lugar bonito! Cheio de árvores, aqui era bem agradável antigamente, apesar das ruas, eram assim pequenas ainda, não tinha asfalto nem nada, mas tinha aqueles jambeiros, muito bonito o lugar, era bonito (RT, 2018).

Esse formato de cidade, com arborização e jardim, remete ao conceito de cidade hospital, que chegou ao Brasil em 1900. Esse conceito foi aplicado na década de 30, nos leprosários implantados pelo país, criando-se colônias pensadas como verdadeiras aldeias de proscritos (AMORA, 2009). 
Imagem 3 - Procissão Círio de Nossa senhora de Nazaré - 1970

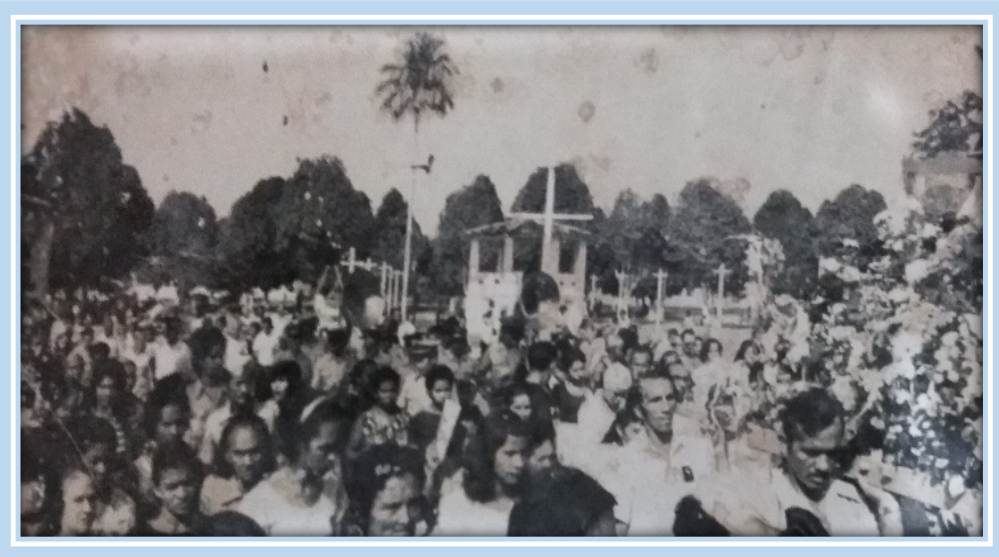

Fonte: Acervo pessoal da intérprete CS, 2017.

A imagem 3 revela um momento religioso que acontecia no segundo domingo do mês de

novembro, o Círio de Nossa Senhora de Nazaré. Esta festa religiosa era comemorada nessa data devido ao fato de os internos não poderem sair para acompanhar as festividades da capital; dessa maneira poderiam acompanhá-las por noticiários ou jornais e, logo em seguida, comemorar a mesma data de maneira interna (Notas de campo).

A imagem também revela uma quantidade significativa de jambeiros. Este tipo de arborização ainda resiste atualmente na antiga Colônia de Marituba, assim como esteve presente nas memórias da intérprete CS:

Eu sei que chamavam aqui cidade dos jambeiros. Que aqui tudo era... jambeiro [...] Eram muito bonitos. Eram de um lado e de outro [...] Lá onde eu morava era carreira assim [...] E aqui também, essa colônia é no formato de um leque. Não sei se já te disseram isso. Tem um formato de um leque (CS, 2017).

Nesse relato, destacamos a organização espacial em forma leque, o que nos aponta a um controle dos corpos internados, onde a entrada e a saída se dariam por um único lugar, como mostra imagem aérea do lugar no ano de sua inauguração: 
Imagem 4 - Imagem aérea do Leprosário de Marituba - 1942

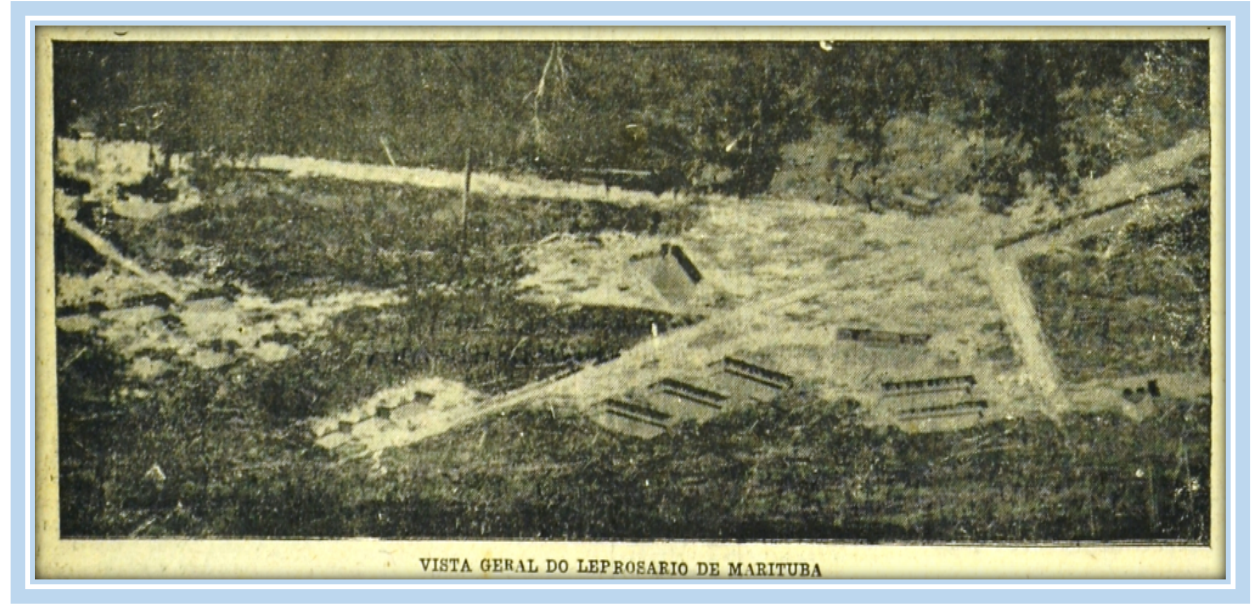

Fonte: Jornal O Estado do Pará, 16 de janeiro de 1942, capa.

Em meio às imagens e narrações até aqui apresentadas, a memória tem adquirido relevante importância em desvendar saberes, períodos históricos, sociedades silenciadas, em que "a memória, portanto, constrói o real, muito mais do que resgata" (BRESCIANI; NAXARA, 2004, p.51). "O ser sensível é como uma testemunha que vem depor sobre aquilo que viu, diante do "eu" que não viu" (HALBWACHS, 2003, p.29).

As imagens são símbolos que, assim como textos e testemunhos orais, apresentam-se também como forma importante de evidência histórica. "Eles registram atos de testemunha ocular" (BURKE, 2017, p. 27). A imagem abaixo mostra como se deu um momento de aprendizagem de RT no curso de técnico de enfermagem, ministrado dentro da Colônia.

Imagem 5: Curso de formação em técnico em enfermagem - Colônia de Marituba

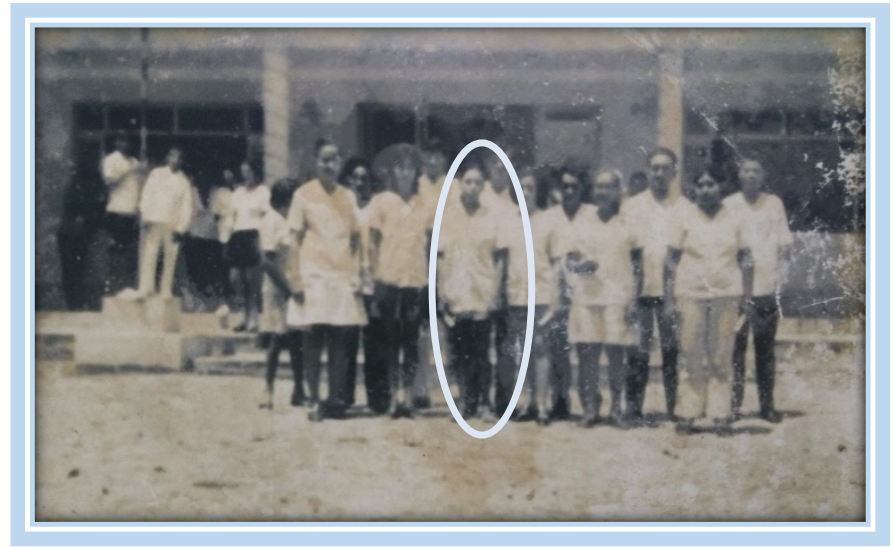

Fonte: Acervo pessoal de RT, 2018. 
Os testemunhos sobre o cotidiano institucional seguem em meio às memórias das intérpretes. Através de imagens e memória, estabeleceu-se o ponto de contato (HALBWACHS, 2003), para que, assim, as lembranças de quais os narradores recordam encontrem um fundamento comum.

As experiências e rememorações que o ancião traz em registros do que se passou possibilitao, mediante a memória, desenvolver imagens do passado (BOSI, 1994). Estas recordações descrevem como se deram algumas experiências educativas:

Era, a costurar! Tudo ela ensinava a bordar! Ela ensinava a bordar, a única coisa que ela não ensina era crochê, que a gente tinha outra professora pra fazer... acho que devido a mão dela, né? A mãozinha era ruim, mas o bordado ela dizia, pegava o pano e dizia como era pra "nós fazer"... tinha "lençóis lá marcado" muito bonitos, que as meninas marcavam (CS, 2017).

Tinham muitos cursos, tinha datilografia, tinha pintura, tinha curso de corte costura... tinha até um curso de marcenaria para os meninos, tinha muitos cursos no Centro Social, na época que funcionava direitinho o Centro Social, aí muita gente aprendeu (RT, 2018).

O centro social, seria um espaço que abrigaria alguns cursos, conforme o relato. $\mathrm{O}$ espaço foi um lugar de circulação de aprendizagem e lugar de mostra de trabalhos feitos pelos internos. A imagem 6 mostra a inauguração do lugar.

Imagem 6 - Inauguração do Centro Social - Colônia de Marituba

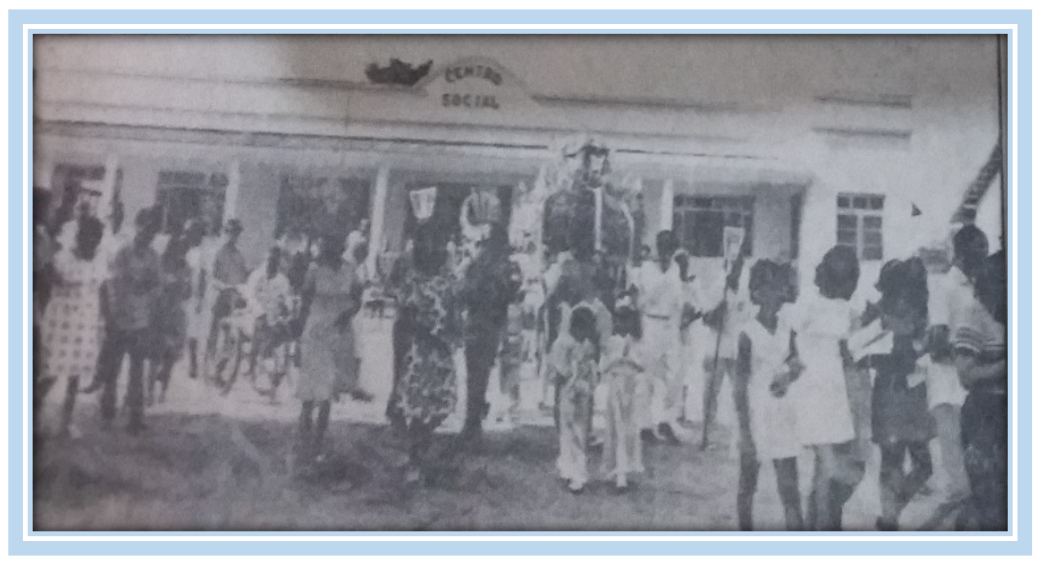

Fonte: Acervo pessoal de CS, 2017.

A reunião de pessoas em torno de um fazer ocorria em diversos momentos da vida do interno. Festejos de datas comemorativas como carnaval e festa junina também marcaram a memória das internas:

Movimento assim... tinha a festa junina, tinha a quadrilha, a minha avó colocava as quadrilhas, aí faziam as brincadeiras de corrida de saco, tudo aqui tinha... tudo o que 
tu podes pensar aqui tinha. Só era assim, que "tu não podia" sair, mas tudo aqui tinha. Tinha carnaval (CS, 2017).

O pessoal aí... tinha um senhor que se chamava Brasil, o apelido dele era Brasil, ele que organizava, ele que ensaiava, aí a gente dançava... as pessoas convidavam, vai lá em casa dançar, a gente ia, nos pavilhões, dançava, aí no cassino... aí quando a gente ia dançar no cassino, todo mundo ia pra lá olhar a gente dançar (RT, 2018).

Coadunando com a informação sobre os festejos juninos, CS mostra uma foto de uma apresentação de festa junina na década de 70, no Hospital Colônia:

Imagem 7 - Apresentação da quadrilha junina - 1970

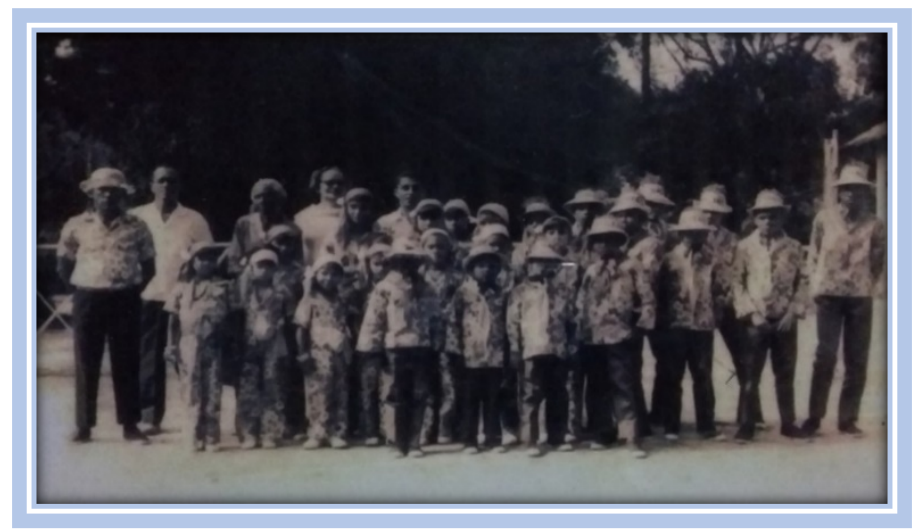

Fonte: Acervo pessoal de CS, 2017.

Outras apresentações também ocorriam no Cassino da Colônia. No Cassino, espaço de diversão, ocorriam apresentações de filmes, pássaros juninos, peças de natal, entre outros eventos. Os internos tinham nele seu ponto de encontro social. Apenas os Hospitais Colônias de grande porte possuíam esse espaço (CASTRO, 2017), o que aponta a Colônia de Marituba como um leprosário de grande porte.

As recordações sobre o espaço aparecem em narração da CS:

Era, isso mesmo! E tinha o cassino... e nesse cassino vinham os pássaros, de Belém, esses negócios de... E vinham pra gente assistir [...]. Enchia o cassino. Muito movimentado... era pássaro mesmo de Belém!!! E daqui era pastorinha que faziam pro natal. O nascimento que era de Jesus, aí era bonito (CS, 2017).

As recordações por meio da memória de idosos podem auxiliar no descrever e refazer de períodos históricos. Os acervos pessoais do idoso - fotografias e lembranças - trazem em si marcas que foram guardadas no baú do coração, experiências que possibilitam o tocar a alma, e este tocar propicia a reconstrução de si ao narrar cada fato passado (PASSEGI, 2011). 
Mas se os idosos são guardiões de conhecimentos, por que então a sociedade insiste em desprezá-los? Segundo Bosi (1994), talvez tenha decaído a arte de trocar experiências, a arte de escutar. $\mathrm{O}$ mundo moderno talvez tenha tomado todo o tempo de troca de experiências.

\section{Conclusão}

Estigmatizados, segregados, marcados por um período de internação, os remanescentes da antiga Colônia de Marituba ainda habitam o local com suas memórias sobre um passado pouco explorado. Lutam por um lugar, junto à sociedade, de reconhecimento e resguardo de tudo o que foi produzido, vivido e deixado. Com políticas sociais que pouco favorecem o meio, vem-se degradando o sujeito duplamente estigmatizado, idoso e hanseniano, insistindo-se em deixá-lo à margem de tudo.

Os sujeitos foram marcados por inúmeras experiências que vivenciaram ao longo de suas vidas. Experiências de amor, rancor, aprendizado, lutas e ressignificações. Memórias narradas que asseguram ao ancião a competência de rememorar, reconstituir e ensinar aos ouvidos dispostos a escutar.

Essas são memórias de vidas que redesenham o passado para que os olhos de hoje possam ver e conhecer (EIRÓ, 2017), unidas a imagens “que nunca são evidências da história: elas próprias são a história" (BURKE, 2017, p. 39); memórias e imagens das quais o uso é mais um suporte historiográfico para o refazer de períodos históricos.

Hansenianos, sujeitos estigmatizados, sim, mas nunca livres de ricas experiências vividas em um passado pouco explorado; hoje, em meio às reviravoltas em que a história oral proporcionou a validação desses testemunhos como "documentos vivos" (MEIHY; HOLANDA, 1997), trazem em si a missão de contribuir junto à historiografia com suas memórias e recordações de momentos históricos.

A memória apresenta-se com a função de elucidar o passado e a imagem como suporte da memória, pinçando momentos únicos e adormecidos em meio às lembranças individuais. Hoje, as memórias dos internos representam a possibilidade de contar de outra forma a história dos vencidos, que agora triunfam como vencedores de um passado sofrido. Vencedores, porque resistiram a um sistema punitivo institucional-estatal, e que, por meio da memória, podem traçar novos rumos de uma história turva.

As memórias expressas neste trabalho vêm apontar diversos aspectos que precisam ser estudados, clarificados. Que estas evidências aqui escritas sirvam de reflexão sobre um modelo institucional implantado na Amazônia, assim como estimule mais pesquisas sobre a temática, pois 
muitas são as lacunas históricas sobre a lepra no Pará. As memórias colhidas e as imagens rememoradas neste artigo foram escolhidas para um propósito: reconstituir e contribuir com a historiografia amazônica.

\section{Referências}

AMORA, Ana Albano. Utopia ao avesso nas cidades muradas da hanseníase: apontamentos para a documentação arquitetônica e urbanística das colônias de leprosos no Brasil. Cadernos de História e Ciência. São Paulo, v. 5, n. 1, p. 23-53, 2009.

BERGSON, Henri. Textos escolhidos por Gilles Deleuze. Trad. Claudia Berliner. São Paulo: Martins Fontes, 2006.

BOSI, Ecléa. Memória e sociedade: lembranças de velhos. $3^{\text {a }}$ ed. São Paulo: Companhia das Letras, 1994.

BRASIL. Lei $\mathbf{n}^{\circ} \mathbf{9 . 0 1 0}$, de março de $1995 . \quad$ Disponível https://presrepublica.jusbrasil.com.br/legislacao/127430/lei-9010-95. Acesso em: 24 jan. 2018.

BRASIL. Manual de Leprologia. Publicado pelo Serviço Nacional da Lepra, Rio de Janeiro, Gráfica da Revista dos Tribunais S. A., 1960. Disponível em: http//bvsms.saude.gov.br/bvs/publicações/manual_leprologia.pdf. Acesso em: 30 abr. 2017.

BRASIL, Ministério da Saúde. Tratado de Leprologia. Publicado pelo Serviço Nacional da Lepra. 2 ed. v. II. Rio de Janeiro, 1950.

BRESCIANI, Stella; NAXARA, Márcia. Memória e (re)sentimento: indagações sobre uma questão sensível. $2^{\mathrm{a}}$ ed. Campinas: Editora Unicamp, 2004.

BURKE, Peter. Testemunha ocular: uso de imagens como evidência histórica. Trad. Vera Maria Xavier dos Santos. São Paulo: Editora Unesp, 2017.

CASTRO, Manuela. A Praga. São Paulo: Geração Editorial, 2017.

CERTEAU, Michel de. A invenção do cotidiano: as artes do fazer. Petrópolis: Vozes,1998. 
EIRÓ, Jessiléia Guimarães. As palavras nas memórias dos mestres: um resgate do coração. In: FARES, Josebel A. (org.). Memória de mestre: Belém antiga em narrativas de professores. $1^{\mathrm{a}}$ ed. Belém: Editora Paka-Tatu, 2017. p. 85-132.

FOLHA DO NORTE, Belém, 15 de janeiro de 1942. Arquivo do setor de Obras raras da Biblioteca Arthur Viana.

GOFFMAN, Erving. Manicômios, prisões e conventos. Trad. Dante Moreira Leite. São Paulo: Perspectiva, 1974.

HALBWACHS, Maurice. A memória coletiva. Trad. Beatriz Sidou. $2^{\mathrm{a}}$ ed. São Paulo: Centauro, 2003.

MEIHY, José Carlos Sebe B.; HOLANDA, Fabíola. História oral: como fazer como pensar. $2^{\mathrm{a}}$ ed. São Paulo: Contexto, 2017.

MENEZES, Adélia Bezerra. Memória coletiva e individual. In: ensaios de literatura e psicanálise. São Paulo: Duas cidades, 1995. p. 29-56.

Do poder da palavra:

O ESTADO DO PARÁ, Belém, 16 de janeiro de 1942. Arquivo do setor de Obras raras da Biblioteca Arthur Viana.

PASSEGGI, Maria da Conceição. A experiência em formação. Revista Educação. Porto Alegre, v. 34, n. 2, p. 147-156, mai./ago., 2011.

SOUZA-ARAÚJO, Heráclides Cesar. História da lepra no Brasil: álbum das organizações antileprosas. Período republicano (1889-1946), v. 2. Rio de Janeiro: Imprensa Nacional, 1948.

. Relatórios de uma viagem de estudos ao redor da América do Sul: Observações de médicos sanitaristas. In: Memórias do instituto Oswaldo Cruz. Tomo 36, fascículo 2, 1941. Disponível em: http://www.scielo.br/pdf/mioc/v36n2/tomo36(f2) 99-200.pdf. Acesso em: 2 fev. 2018. 